\title{
Synthesis and asymmetric polymerization of chiral maleimides bearing an aza crown ether
}

\author{
Motohisa Azechi, Jun Iwai, Kazuhiro Yamabuki, Kenjiro Onimura and Tsutomu Oishi
}

Chiral $N$-substituted maleimide derivatives bearing L-phenylalanine- or L-leucine-introduced aza crown ether ((S)-A15C5PAMI, (S)-A15C5LMI) were synthesized from maleic anhydride, corresponding amino acids and aza crown ether, and polymerized with an organometal/chiral ligand. The number-average-molecular weights and the specific optical rotations of the polymers were 700-5600 and $-105.8^{\circ}$ to $-38.3^{\circ}$, respectively. The specific optical rotations of all polymers tended to a positive direction, compared with model compounds $\left((S)-A 15 C 5 P A S I\left([\alpha]_{435}=-218.1^{\circ}\right),(S)-A 15 C 5 L S I\left([\alpha]_{435}=-215.1^{\circ}\right)\right)$. Asymmetric inductions in the main chains of the polymers were investigated by the measurements of specific optical rotation, circular dichroism. Polymer Journal (2011) 43, 279-284; doi:10.1038/PJ.2010.139; published online 19 January 2011

Keywords: amino acid; anionic polymerization; asymmetric polymerization; aza crown ether; maleimide

\section{INTRODUCTION}

The synthesis of optically active polymers is interesting from the standpoints of the formation process, stereoregularity and asymmetric functionality. The optical activity of these polymers is dependent on the main chain forming a one-handed helical structure. The main chain structure of these optically active polymers is very important for special functions such as molecular recognition and asymmetric catalysis. To artificially form a one-handed helical structure, it is necessary to synthesize an optically active polymer by asymmetric polymerization. For example, Okamoto and coworkers ${ }^{1-4}$ reported that the polymers obtained from the asymmetric polymerization of methacrylate derivatives bearing bulky substituents showed substantial optical activity on the basis of one-handed helical conformations.

$\mathrm{N}$-Substituted maleimides (RMIs) have been well known as a type of attractive monomer that provides optically active polymers through asymmetric anionic polymerization., ${ }^{5,6}$ Because the RMI has a 1,2disubstituted structure, poly(RMI) can be presumed to produce four types of structures: threo-diisotactic, threo-disyndiotactic, erythrodiisotactic and erythro-disyndiotactic. Erythro-diisotactic and erythro-disyndiotactic structures cannot be formed with cis-additional reactions because of steric hindrance among monomeric units due to carbonyl groups in the imide rings. ${ }^{7}$ Trans-additional structures, that is, threo-diisotactic and threo-disyndiotactic structures, can be formed during the polymerization of RMI. Threo-disyndiotactic structures show no optical activity because the $(S, S)$ - and $(R, R)$-configurational pairs exist at equivalent levels in the polymer main chains. Poly(RMI) with a threo-diisotactic structure can show optical activity when one of the asymmetric carbon pairs in the monomer unit exists in excess. Furthermore, the high continuity of the same configurational pair
$((S, S)$ or $(R, R))$ in the threo-diisotactic structures may allow for a helical conformation.

We have systematically investigated the asymmetric anionic polymerizations of RMIs bearing various $N$-substituents derived from achiral amine, chiral amine and chiral amino-acid derivatives with organometallic/chiral ligand complexes. ${ }^{6,8-17}$ Among the optically active poly(RMI)s, the RMI with an achiral 1-naphthyl or a chiral (S)-methylbenzyl group as an $\mathrm{N}$-substituent showed the highest specific optical rotation in chloroform $\left([\alpha]_{435}=+762.3^{\circ},+551.7^{\circ}\right){ }^{10-12}$ Recently, we reported on the asymmetric polymerizations of achiral maleimide bearing an achiral benzo crown ether and additional effects of the chiral amine on the achiral polymers. ${ }^{17}$ However, there have been no reports on the asymmetric polymerization of chiral maleimide bearing an amino-acid moiety and aza crown ether derivatives.

Crown ether is a cyclic ether derivative and has attracted a great deal of attention as a host molecule that can incorporate metal cations $\left(\mathrm{M}^{+}\right)$and alkyl ammonium salts $\left(\mathrm{R}^{-} \mathrm{NH}_{3}{ }^{+}\right)$as guest molecules. These complexes are formed by dipole-dipole interactions between the crown ether and the metal cations or ammonium salts. Recently, polymers bearing various crown ethers have been investigated. For example, Yashima and co-workers ${ }^{18-22}$ and Kakuchi and co-workers ${ }^{23-}$ ${ }^{26}$ reported that poly(phenylacetylene) and poly(isocyanate) bearing an aza crown ether or a benzo crown ether induced a one-handed helical structure upon the addition of chiral alkyl ammonium salts, chiral amino alcohols and chiral amino acids.

In this study, chiral maleimides bearing an aza 15-crown-5 ether ((S)-A15C5LMI and (S)-A15C5PAMI) were synthesized from maleic anhydride, the corresponding amino acids and the aza 15-crown-5 ether. Asymmetric anionic polymerizations of (S)-A15C5LMI and 
(S)-A15C5PAMI were performed with an organometal and a chiral ligand complex as initiators (Scheme 1). Chiroptical properties and structures of the polymers were investigated by specific optical rotations, gel permeation chromatography and circular dichroism (CD) measurements. In addition, the effect of $(S)$ - or $(R)$-cyclohexylethylamine $((R)-\mathrm{Cyc})$ on the polymer obtained by radical polymerization was investigated by $\mathrm{CD}$ and ultraviolet (UV) spectra of the polymer.

\section{EXPERIMENTAL PROCEDURE}

\section{Materials}

Solvents used for syntheses, polymerizations and measurements were purified by distillation using sodium metal. $n$-Butyllithium ( $n$-BuLi) (Kanto Chemical, Tokyo, Japan, in $n$-hexane, $1.55 \mathrm{moll}^{-1}$ ) was used as purchased. Diethylzinc $\left(\mathrm{Et}_{2} \mathrm{Zn}\right.$ ) (in $n$-hexane, $1.04 \mathrm{moll}^{-1}$ ) was kindly supplied by Tosoh (Tokyo, Japan). (-)-Sparteine (Tokyo Chemical Industry, Tokyo, Japan) was used after purification by distillation under reduced pressure $\left([\alpha]_{435}=-10.3^{\circ}\right.$, $c=1.0 \mathrm{~g} \mathrm{dl}^{-1}, l=10 \mathrm{~cm}$, tetrahydrofuran (THF)). (S, S)-(1-Ethylpropylidene)bis(4-benzyl-2-oxazoline) $((S, S)$-Bnbox) was prepared as reported previously
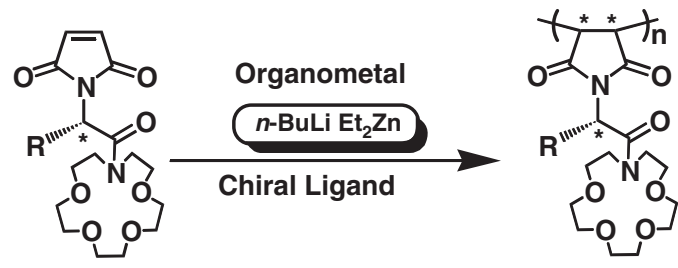

(S)-A15C5RMI poly((S)-A15C5RMI)
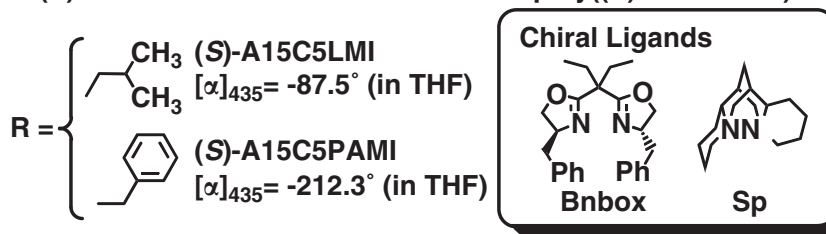

Scheme 1 Anionic polymerization of A15C5RMI. $\left([\alpha]_{435}=-123.5^{\circ}, c=1.0 \mathrm{~g} \mathrm{dl}^{-1}, l=10 \mathrm{~cm}, \mathrm{THF}\right) .{ }^{27-29} 2,2^{\prime}$-Azobisisobutylonitrile (Ishidzu Seiyaku, Osaka, Japan) was used after recrystallization from methanol.

\section{Syntheses of monomers}

The synthetic route of $N$-substituted maleamic acid (RMA: R = L-leucine $((S)$ LMA); R = L-phenylalanine ((S)-PAMA)), $N$-substituted maleimide (RMI: R = L-leucine ((S)-LMI); R = L-phenylalanine $((S)$-PAMI)), and $N$-substituted maleimide having aza 15-crown-5 ether (A15C5RMI: $\mathrm{R}=\mathrm{L}$-leucine $((S)$ A15C5LMI); R = L-phenylalanine ((S)-A15C5PAMI)) is shown in Scheme 2.

\section{(S)-(-)-N-maleamic acid-L-leucine}

A solution of maleic anhydride $(22.5 \mathrm{~g}, 0.23 \mathrm{~mol})$ in acetic acid $(100 \mathrm{ml})$ was added dropwise to a solution of L-leucine $(30.0 \mathrm{~g}, 0.23 \mathrm{~mol})$ in acetic acid $(200 \mathrm{ml})$ at room temperature. After being stirred for $24 \mathrm{~h}$ at the same temperature, the reaction mixture was distilled under reduced pressure to remove acetic acid and then crystallized from diethyl ether. After being filtered and dried under vacuum, $(S)$-LMA was obtained as a white powder (yield: 49.5 g $(94.4 \%)$, m.p.: $\left.134-136.5^{\circ} \mathrm{C}\right) .{ }^{1} \mathrm{H}$ nuclear magnetic resonance (NMR) ( $\delta$ in p.p.m. from tetramethylsilane (TMS) in DMSO- $\left.\mathrm{d}_{6}\right)$ : 9.22-9.20 (d, $\left.1 \mathrm{H}, \mathrm{NH}\right)$, 6.51-6.34 (dd, $2 \mathrm{H},-\mathrm{CH}=\mathrm{CH}-)$, 4.43-4.34 (dd, $1 \mathrm{H},-\mathrm{CH}-), 1.92-1.62(\mathrm{~m}, 2 \mathrm{H}$, $\left.-\mathrm{CH}_{2}-\right), 1.58\left(\mathrm{~m}, 1 \mathrm{H},-\mathrm{CH}\left(\mathrm{CH}_{3}\right)_{2}\right), 0.99-0.93\left(\mathrm{dd}, 6 \mathrm{H},-\mathrm{CH}_{3}\right)$.

\section{(S)-(-)-N-maleoyl-L-leucine}

(S)-LMA (10.0 g, $44 \mathrm{mmol}$ ) was suspended in dry toluene (300 ml), and $\mathrm{H}_{3} \mathrm{PO}_{4}$ $(85 \%, 0.8 \mathrm{~g}, 8.2 \mathrm{mmol})$ and triethylamine $(12.3 \mathrm{ml}, 87 \mathrm{mmol})$ were added in sequence. Then the reaction mixture was refluxed for $1 \mathrm{~h}$ with vigorous stirring. The mixture was cooled to room temperature and an organic solution was concentrated. The obtained residue was neutralized with $6 \mathrm{~N} \mathrm{HCl}$ aq. to $\mathrm{pH}=2$ and extracted with ethyl acetate $(100 \mathrm{ml} \times 3)$. The organic phase was fully washed with water $(100 \mathrm{ml} \times 3)$ and saturated $\mathrm{NaCl}$ aq. $(100 \mathrm{ml})$ in sequence, dried over $\mathrm{Na}_{2} \mathrm{SO}_{4}$, concentrated under reduced pressure, and crystallized in $n$-hexane to yield (S)-LMI as a white powder (yield: $5.7 \mathrm{~g}(61.9 \%)$, m.p.: $88-$ $\left.89.5^{\circ} \mathrm{C}\right) .{ }^{1} \mathrm{H}$ NMR $(\delta$ in p.p.m. from TMS): $6.74(\mathrm{~s}, 2 \mathrm{H},-\mathrm{CH}=\mathrm{CH}-), 4.82-4.77$ (dd, $1 \mathrm{H}, J=4.29,4.62 \mathrm{~Hz},-\mathrm{CH}), 2.31-1.81\left(\mathrm{~m}, 2 \mathrm{H},-\mathrm{CH}_{2}-\right), 1.58(\mathrm{~m}, 1 \mathrm{H}$, $\left.-\mathrm{CH}\left(\mathrm{CH}_{3}\right)_{2}\right), 0.94-0.91\left(\mathrm{dd}, 6 \mathrm{H},-\mathrm{CH}_{3}\right)$.

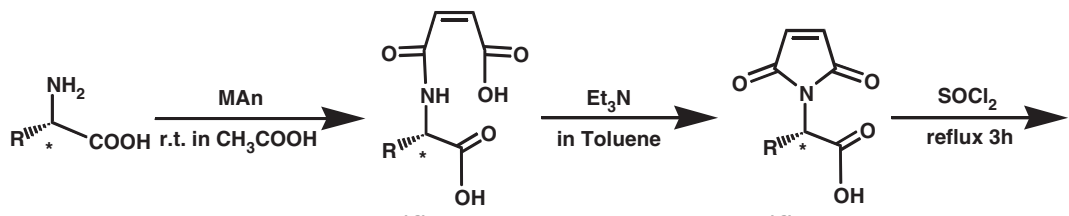

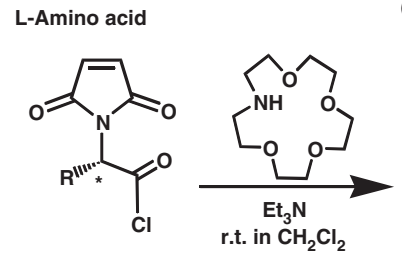

(S)-RMI-CI
(S)-RMA

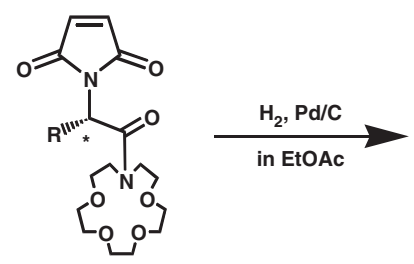

(S)-A15C5RMI

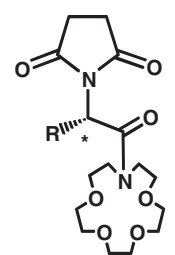

(S)-A15C5RSI

\begin{tabular}{|c|c|c|}
\hline $\mathbf{R}=$ & $\begin{array}{c}(S)-A 15 \text { C5LMI } \\
{[\alpha]_{435}=-87.5^{\circ} \text { (inTHF) }} \\
\text { Yield } 66 \%\end{array}$ & $\begin{array}{c}(S)-A 15 \text { C5LSI } \\
{[\alpha]_{435}=-215.1^{\circ} \text { (inTHF) } .} \\
\text { Yield } 95 \%\end{array}$ \\
\hline & $\begin{array}{c}\text { (S)-A15C5PAMI } \\
{[\alpha]_{435}=-212.3^{\circ} \text { (inTHF) }} \\
\text { Yield } 62 \%\end{array}$ & $\begin{array}{c}\text { (S)-A15C5PASI } \\
{[\alpha]_{435}=-218.1^{\circ} \text { (inTHF). }} \\
\text { Yield } 97 \%\end{array}$ \\
\hline
\end{tabular}

Scheme 2 Synthesis of the monomer and model compounds. 


\section{(S)-(-)-N-maleoyl-L-leucine-aza-15-crown-5}

$(S)$-LMI $(1.3 \mathrm{~g}, 6.3 \mathrm{mmol})$ was dissolved into thionyl chloride $\left(\mathrm{SOCl}_{2} ; 8.0 \mathrm{ml}\right)$, and the solution was refluxed for $3 \mathrm{~h}$. After being cooled to room temperature, excess $\mathrm{SOCl}_{2}$ was removed under reduced pressure, and the residue ((S)-LMI$\mathrm{Cl})$ was dissolved into dry dichloromethane $(30 \mathrm{ml})$. The 1-aza 15-crown-5 ether (Tokyo Chemical Industry, $1.0 \mathrm{~g}, 4.6 \mathrm{mmol}$ ) and triethylamine $(1.7 \mathrm{ml}$, $12.1 \mathrm{mmol}$ ) were dissolved into dry dichloromethane $(30 \mathrm{ml})$, and the solution was cooled to $0{ }^{\circ} \mathrm{C}$. (S)-LMI-Cl in dry dichloromethane was added dropwise into the above solution. Then the reaction solution was stirred at room temperature for $24 \mathrm{~h}$. The solution was washed with $1 \mathrm{~N}$ hydrochloric acid, water and saturated $\mathrm{NaCl}$ (aq) and dried over $\mathrm{Na}_{2} \mathrm{SO}_{4}$. The solution was concentrated by a rotary evaporator to obtain crude (S)-A15C5LMI. The residue was purified by column chromatography (eluent: ethyl acetate) using silica gel as a stationary phase, and (S)-A15C5LMI was obtained as a yellow liquid (yield: $1.8 \mathrm{~g}(66 \%),[\alpha]_{435}=-87.5^{\circ}\left(c=1.0 \mathrm{~g} \mathrm{dl}^{-1}, l=10 \mathrm{~cm}\right.$, THF)). ${ }^{1} \mathrm{H}$ NMR ( $\delta$ in p.p.m. from TMS): 6.68 (s, 2H, $-\mathrm{CH}=\mathrm{CH}-$ ), 5.09-5.01 (q, 1H, $-\mathrm{CH}), 3.98-3.34(\mathrm{~m}, 20 \mathrm{H}$, aza 15-crown-5 ether), 2.57-1.61 (m, $2 \mathrm{H}$, $\left.-\mathrm{CH}_{2}-\right), 1.45\left(\mathrm{~m}, 1 \mathrm{H},-\mathrm{CH}\left(\mathrm{CH}_{3}\right)_{2}\right), 0.94\left(\mathrm{~d}, 6 \mathrm{H},-\mathrm{CH}_{3}\right),{ }^{13} \mathrm{C}$ NMR $(\delta$ in p.p.m. from TMS): $170.7(\mathrm{~N}-\mathrm{C}=\mathrm{O}), 168.9\left(\mathrm{C}^{*}-\mathrm{C}=\mathrm{O}\right), 134.1(-\mathrm{CH}=\mathrm{CH}-)$, 71.6-69.1, 50.4-49.9 (aza 15-crown-5 ether), $49.5\left(-\mathrm{C}^{\star} \mathrm{H}\right), 36.9\left(-\mathrm{CH}_{2}-\right)$, $25.2\left(-\mathrm{CH}\left(\mathrm{CH}_{3}\right)_{2}\right), 23.1-21.1\left(-\mathrm{CH}_{3}\right)$, time of flight mass spectrometry (TOF MS) (ES+ $[\mathrm{M}+\mathrm{H}]^{+}$) calculated value for $\mathrm{C}_{20} \mathrm{H}_{32} \mathrm{~N}_{2} \mathrm{O}_{7}: \mathrm{m} / z$ 412.22; observed value: $m / z$ 412.21.

\section{(S)-(-)-N-maleamic acid-L-phenylalanine}

(S)-PAMA was synthesized from L-phenylalanine $(41.3 \mathrm{~g}, 0.25 \mathrm{~mol})$ and maleic anhydride (24.5 g, $0.25 \mathrm{~mol}$ ) by a method similar to that used for (S)-LMA. (S)PAMA was obtained as a white powder (yield: $59.5 \mathrm{~g}$ (90.4\%), m.p.: 125.7$\left.126.3{ }^{\circ} \mathrm{C}\right) .{ }^{1} \mathrm{H}$ NMR $\left(\delta\right.$ in p.p.m. from TMS in DMSO-d $\left.\mathrm{d}_{6}\right)$ : 9.22-9.20 (d, $1 \mathrm{H}$, $\mathrm{NH}), 7.29-7.22(\mathrm{~m}, 5 \mathrm{H}, \mathrm{Ph}), 6.49-6.26(\mathrm{dd}, 2 \mathrm{H},-\mathrm{CH}=\mathrm{CH}-), 4.61-4.50$ (dd, $1 \mathrm{H},-\mathrm{CH}-), 3.18-2.87\left(\mathrm{~m}, 2 \mathrm{H},-\mathrm{CH}_{2}-\right)$.

\section{(S)-(-)-N-Maleoyl-L-phenylalanine}

$(S)$-PAMI was synthesized from (S)-PAMA $(10.0 \mathrm{~g}, 38 \mathrm{mmol})$ by a method similar to that used for (S)-LMI synthesis. (S)-PAMI was obtained as a white powder (yield: $4.6 \mathrm{~g}(49.2 \%)$, m.p.: $\left.158.0-158.5^{\circ} \mathrm{C}\right) .{ }^{1} \mathrm{H}$ NMR $(\delta$ in p.p.m. from TMS): 7.31-7.14 (m, 5H, Ph), $6.61(\mathrm{~s}, 2 \mathrm{H},-\mathrm{CH}=\mathrm{CH}-), 5.01(\mathrm{q}, 1 \mathrm{H},-\mathrm{CH})$, $3.57-3.45\left(\mathrm{~m}, 2 \mathrm{H},-\mathrm{CH}_{2}-\right)$.

\section{(S)-(-)-N-maleoyl-t-phenylalanine-aza-15-crown-5}

$(S)$-A15C5PAMI was synthesized from $(S)$-PAMI $(1.6 \mathrm{~g}, 6.3 \mathrm{mmol})$ and the 1 aza 15 -crown-5 ether $(1.0 \mathrm{~g}, 4.6 \mathrm{mmol})$ by a method similar to that used for the synthesis of (S)-A15C5LMI. The obtained crude (S)-A15C5PAMI was purified by column chromatography (eluent: $n$-hexane/acetone $=1 / 1$ ) using silica gel as a stationary phase, and $(S)$-A15C5PAMI was obtained as a yellow liquid (yield: $\left.1.7 \mathrm{~g}(62 \%),[\alpha]_{435}=-212.3^{\circ}\left(c=1.0 \mathrm{~g} \mathrm{dl}^{-1}, l=10 \mathrm{~cm}, \mathrm{THF}\right)\right) .{ }^{1} \mathrm{H}$ NMR $(\delta$ in p.p.m. from TMS): 7.34-7.15 (m, 5H, Ph), 6.57 (s, 2H, $-\mathrm{CH}=\mathrm{CH}-)$, 5.29-5.18 (q, $1 \mathrm{H},-\mathrm{CH}), 3.90-3.42(\mathrm{~m}, 20 \mathrm{H}$, aza $15-$ crown-5 ether), 3.42-3.26 (m, $2 \mathrm{H},-$ $\left.\mathrm{CH}_{2}-\right),{ }^{13} \mathrm{C}$ NMR ( $\delta$ in p.p.m. from TMS): $170.2(\mathrm{~N}-\mathrm{C}=\mathrm{O}), 168.9\left(\mathrm{C}^{\star}-\mathrm{C}=\mathrm{O}\right)$, 137.2 (ipso carbon in phenylalanine residue), $134.1(-\mathrm{CH}=\mathrm{CH}-), 71.8,70.0$, 69.8, 69.1, 52.7, 50.2 (aza 15-crown-5 ether), $49.8\left(-\mathrm{C}^{*} \mathrm{H}\right), 35.0\left(-\mathrm{CH}_{2}-\right)$. TOF MS (ES+ $\left.[\mathrm{M}+\mathrm{H}]^{+}\right)$calculated value for $\mathrm{C}_{23} \mathrm{H}_{30} \mathrm{~N}_{2} \mathrm{O}_{7}: \mathrm{m} / z$ 446.21; observed value: $m / z 446.18$.

\section{Syntheses of model compounds}

The synthetic route of model compounds for the polymers is shown in Scheme 2.

\section{(S)-(-)-N-succinoyl-L-leucine-aza-15-crown-5}

(S)-A15C5LMI $(0.17 \mathrm{~g}, 0.41 \mathrm{mmol})$ was placed in a Schlenk reaction tube, and ethyl acetate $(10 \mathrm{ml})$ was added to dissolve it. Palladium-activated carbon (10\%) (Aldrich Chemical, Milwaukee, WI, USA, $0.017 \mathrm{~g}, 10 \mathrm{wt} \%$ ) was added to the solution. The tube was evacuated with an aspirator and replaced with hydrogen gas five times, and the solution was stirred under a hydrogen atmosphere for $24 \mathrm{~h}$. The reaction mixture was evacuated with an aspirator, replaced with nitrogen gas, and then filtered to remove the $10 \%$ palladiumactivated carbon. The filtrate was concentrated under reduced pressure to yield $(S)-(-)-N$-succinoyl-L-leucine-aza-15-crown-5 ((S)-A15C5LSI) (yield: $0.16 \mathrm{~g}$ (95\%), $\left.[\alpha]_{435}=-215.1^{\circ}\left(c=1.0 \mathrm{~g} \mathrm{dl}^{-1}, l=10 \mathrm{~cm}, \mathrm{THF}\right)\right) .{ }^{1} \mathrm{H}$ NMR $(\delta$ in p.p.m. from TMS): $5.06-5.00(\mathrm{q}, 1 \mathrm{H},-\mathrm{CH}), 3.86-3.25(\mathrm{~m}, 20 \mathrm{H}$, aza 15-crown-5 ether), 2.77-2.62 (m, $\left.4 \mathrm{H},-\mathrm{CH}_{2}-\mathrm{CH}_{2}-\right), 2.38,1.62\left(\mathrm{~m}, 2 \mathrm{H},-\mathrm{CH}_{2}-\right), 1.43$ $\left(\mathrm{m}, 1 \mathrm{H},-\mathrm{CH}\left(\mathrm{CH}_{3}\right)_{2}\right), 0.92\left(\mathrm{~d}, 6 \mathrm{H},-\mathrm{CH}_{3}\right),{ }^{13} \mathrm{C}$ NMR $(\delta$ in p.p.m. from TMS): $177.1(\mathrm{~N}-\mathrm{C}=\mathrm{O}), 169.4\left(\mathrm{C}^{\star}-\mathrm{C}=\mathrm{O}\right), 71.6,70.6,70.2,70.1,69.9,69.6$ 68.9, 50.7, 49.6 (aza 15-crown-5 ether), $49.3\left(-\mathrm{C}^{\star} \mathrm{H}\right), 36.7\left(\mathrm{C}^{\star} \mathrm{H}-\mathrm{CH}_{2}-\right), 28.0\left(-\mathrm{CH}_{2}-\right.$ $\left.\mathrm{CH}_{2}-\right), 25.1\left(-\mathrm{CH}\left(\mathrm{CH}_{3}\right)_{2}\right), 23.0,21.4\left(-\mathrm{CH}_{3}\right)$. TOF MS (ES+ $\left.[\mathrm{M}+\mathrm{H}]^{+}\right)$ calculated value for $\mathrm{C}_{20} \mathrm{H}_{34} \mathrm{~N}_{2} \mathrm{O}_{7}: \mathrm{m} / z$ 414.24; observed value: $\mathrm{m} / z 414.21$.

\section{(S)-(-)-N-succinoyl-L-phenylalanine-aza-15-crown-5}

(S)-(-)- $N$-succinoyl-L-phenylalanine-aza-15-crown-5 ((S)-A15C5PASI) was synthesized from $(S)$-A15C5PAMI $(0.27 \mathrm{~g}, 0.60 \mathrm{mmol})$ by a method similar to that used for the synthesis of (S)-A15C5LSI (yield: $0.26 \mathrm{~g}(97 \%),[\alpha]_{435}=-218.1^{\circ}$ $\left.\left(c=1.0 \mathrm{~g} \mathrm{dl}^{-1}, l=10 \mathrm{~cm}, \mathrm{THF}\right)\right) .{ }^{1} \mathrm{H}$ NMR ( $\delta$ in p.p.m. from TMS): $7.30-7.14$ $(\mathrm{m}, 5 \mathrm{H}, \mathrm{Ph}), 5.23-5.12(\mathrm{q}, 1 \mathrm{H},-\mathrm{CH}), 3.85-3.42(\mathrm{~m}, 20 \mathrm{H}$, aza 15-crown-5 ether), 3.42-3.25 (m, $\left.2 \mathrm{H},-\mathrm{CH}_{2}-\right), 2.70-2.48\left(\mathrm{~m}, 4 \mathrm{H},-\mathrm{CH}_{2}-\mathrm{CH}_{2}-\right),{ }^{13} \mathrm{C} \mathrm{NMR}$ ( $\delta$ in p.p.m. from TMS): $176.7(\mathrm{~N}-\mathrm{C}=\mathrm{O}), 168.5\left(\mathrm{C}^{*}-\mathrm{C}=\mathrm{O}\right), 137.2$ (ipso carbon in phenylalanine residue), $129.0,128.5,127.0(\mathrm{Ph}), 71.3,70.7,70.4,70.0,69.8$, 68.7, 53.2 (aza 15-crown-5 ether), $50.1\left(-\mathrm{C}^{\star} \mathrm{H}\right), 34.8\left(-\mathrm{CH}_{2-}\right), 28.2\left(-\mathrm{CH}_{2}-\right.$ $\left.\mathrm{CH}_{2}-\right)$. TOF MS $\left(\mathrm{ES}+[\mathrm{M}+\mathrm{H}]^{+}\right)$calculated value for $\mathrm{C}_{23} \mathrm{H}_{30} \mathrm{~N}_{2} \mathrm{O}_{7}: \mathrm{m} / \mathrm{z} 448.22$; observed value: $\mathrm{m} / \mathrm{z} 448.20$

\section{Anionic polymerization}

A monomer and a chiral ligand were placed in a Schlenk reaction tube and a pear-shaped flask, respectively. They were evacuated by a vacuum pump and then replaced by nitrogen gas. Polymerization solvent was added to each vessel by a syringe under a nitrogen atmosphere. Organometal $\left(n-\mathrm{BuLi}\right.$ or $\left.\mathrm{Et}_{2} \mathrm{Zn}\right)$ in an $n$-hexane solution was introduced into a chiral ligand solution with a syringe to prepare the initiator complex. The monomer solution was kept at the polymerization temperature. The complex solution was added by a cannula in a stream of nitrogen to initiate the polymerization. Polymerization without the chiral ligand was initiated by adding the organometal in an $n$-hexane solution to a monomer solution directly with a syringe. After a prescribed time, the polymerization was terminated with a small amount of methanol containing two drops of $6 \mathrm{~N}$ aqueous hydrochloric acid. The polymerization solution was concentrated. Dichloromethane was added to the residue, and the solution was washed using $0.1 \mathrm{~N}$ aqueous hydrochloric acid. After the organic layer was concentrated, the residue was purified by reprecipitation from THF- $n$-hexane systems three times. The pure polymers were dried in vacuo at room temperature for 2 days.

\section{Radical polymerization}

Radical polymerization was conducted in a sealed glass tube using 2, 2'azobisisobutylonitrile as an initiator under a nitrogen atmosphere. All reagents were added to the glass tube, and the mixture was degassed three times before the tube was sealed under vacuum. The polymerization was conducted in an oil bath, regulated at $60^{\circ} \mathrm{C}$ for $24 \mathrm{~h}$. The polymerization was terminated by cooling the reaction mixture to $0{ }^{\circ} \mathrm{C}$. The obtained polymer was purified by a method similar to that used in the case of the anionic polymerization.

\section{Measurement}

Specific optical rotations were measured in THF at $25^{\circ} \mathrm{C}$ using a quartz cell $(l=10 \mathrm{~cm})$ with a JASCO DIP-1030 polarimeter (JASCO, Tokyo, Japan). CD and UV spectra were recorded in THF at $25^{\circ} \mathrm{C}$ using a quartz cell of $1 \mathrm{~mm}$ with a JASCO J-805 spectropolarimeter. The number-average-molecular weights $\left(M_{\mathrm{n}}\right)$ of the polymers were measured with gel permeation chromatography using THF $\left(50^{\circ} \mathrm{C}\right)$ as an eluent and polystyrene as the standard with a Shimadzu LC-10A (Shimadzu, Kyoto, Japan) instrument equipped with a Shimadzu HSG-40, HSG-20, HSG-15 and HSG-10 column (i.d.: $7.9 \mathrm{~mm}$, length: $30 \mathrm{~cm}$, gel particle size: $10 \mu \mathrm{m}$, theoretical plate numbers: $>10000$ ), an SPD-10A UV detector, a JASCO OR-990 polarimetric detector and a C-R7Ae plus data processor. ${ }^{1} \mathrm{H}$ and ${ }^{13} \mathrm{C}$ NMR spectra were obtained with JEOL-EX270 (Tokyo, Japan). 


\section{RESULTS AND DISCUSSION}

\section{Polymerization}

The results of the anionic and radical polymerizations of $(S)$ A15C5LMI are summarized in Table 1. The yields and $M_{\mathrm{n}}$ of the polymers obtained with $n$-BuLi were higher than those of the polymers obtained with $\mathrm{Et}_{2} \mathrm{Zn}$. The $M_{\mathrm{n}}$ was $700-3200$ for the polymers obtained by the anionic method and 5300 for the polymers obtained by the radical method.

Table 2 shows the conditions and results of the anionic and radical polymerizations of (S)-A15C5PAMI. The yields and $M_{\mathrm{n}}$ of the polymers obtained by anionic polymerization were $94.8-99.2 \%$ and 1300 2600 , respectively. The yield and $M_{\mathrm{n}}$ of the polymers obtained by radical polymerization were $99.2 \%$ and 5600 , respectively. The anionic polymerization ability of (S)-A15C5PAMI did not depend on the polymerization temperature and chiral ligand. The anionic polymerization ability of (S)-A15C5PAMI and (S)-A15C5LMI indicated a similar tendency.

\section{Optical properties of polymers}

The poly $((S)$-A15C5LMI)s obtained by anionic polymerization had specific optical rotations of $[\alpha]_{435}=-42.7^{\circ}$ to $-75.3^{\circ}$, as shown in Table 1. Compared with the specific optical rotation of (S)-A15C5LSI $\left([\alpha]_{435}=-215.1^{\circ}\right)$ of the model compound for the polymer, specific optical rotations of all poly $((S)-A 15 C 5 \mathrm{LMI})$ s tended to be in a positive direction. The specific optical rotation of poly((S)-A15C5LMI) obtained with $n$-BuLi/Bnbox at $-40{ }^{\circ} \mathrm{C}$ exhibited the most positive change of all of the poly $((S)-A 15 \mathrm{C} 5 \mathrm{LMI}) \mathrm{s}$. This indicates that the stereoregularity of the polymer main chain was controlled by the effects of both the chiral ligand and the polymerization temperature.

CD and UV spectra for (S)-A15C5LMI, (S)-A15C5LSI and the poly $((S)-A 15 C 5 L M I) s$ are shown in Figure 1. Positive and negative cotton effects of poly $((S)$-A15C5LMI) formed by (c) $n$-BuLi/Bnbox, (d) $\mathrm{Et}_{2} \mathrm{Zn} / \mathrm{Sp}$ and (e) 2, 2'-azobisisobutylonitrile appeared around 220 and $250 \mathrm{~nm}$ due to the $n-\pi^{*}$ electric transition of the carbonyl groups. The cotton effects of the poly $((S)-\mathrm{A} 15 \mathrm{C} 5 \mathrm{LMI}) \mathrm{s}$ were different from that of the model compound (S)-A15C5LSI. Therefore, it was suggested that asymmetric induction took place on the polymer main chain as judged from the specific rotation and CD spectra described above.

The $\operatorname{poly}((S)$-A15C5PAMI)s obtained by anionic polymerization had specific optical rotations of $[\alpha]_{435}=-68.5^{\circ}$ to $-105.8^{\circ}$. In comparison with the specific optical rotation of the model compound (S)-A15C5PASI $\left([\alpha]_{435}=-218.1^{\circ}\right)$, specific optical rotations of all of the $\operatorname{poly}((S)-A 15 C 5 P A M I) s$ tended to be in a positive direction. In the

Table 1 Asymmetric anionic and radical polymerization of (S)-A15C5LMIa

\begin{tabular}{|c|c|c|c|c|c|c|c|c|c|}
\hline Run & Initiator ${ }^{b}$ & Polym. solv. $(\mathrm{ml})$ & Polym. temp. $\left({ }^{\circ} \mathrm{C}\right)$ & Polym. time $(h)$ & Conv. $(\%)^{c}$ & Yield $(\%)^{\mathrm{d}}$ & $M_{\mathrm{n}} \times 10^{-3 \mathrm{e}}$ & $M_{\mathrm{w}} / M_{\mathrm{n}}^{\mathrm{e}}$ & {$[\alpha]_{435^{25}}(\text { deg. })^{f}$} \\
\hline 1 & n-BuLi & Tol. (3) & 0 & 24 & 100 & 98.4 & 1.7 & 1.1 & -45.7 \\
\hline 2 & n-BuLi & Tol. (3) & -40 & 72 & 100 & 98.1 & 1.5 & 1.2 & -59.4 \\
\hline 3 & n-BuLi/Bnbox (1/1.2) & Tol. (3) & 0 & 24 & 100 & 99.0 & 2.1 & 1.1 & -75.3 \\
\hline 4 & n-BuLi/Bnbox (1/1.2) & Tol. (3) & -40 & 72 & 100 & 99.3 & $\begin{array}{c}1.4 \\
(14.5,1.3)\end{array}$ & $\begin{array}{c}7.3 \\
(1.7,1.1)\end{array}$ & -42.7 \\
\hline 5 & n-BuLi/Sp (1/1.2) & Tol. (3) & 0 & 24 & 77.2 & 76.7 & 1.9 & 1.1 & -74.2 \\
\hline 6 & n-BuLi/Sp (1/1.2) & Tol. (3) & -40 & 72 & 100 & 99.4 & 3.2 & 1.3 & -62.8 \\
\hline 7 & n-BuLi/Sp (1/1.2) & THF (3) & 0 & 24 & 63.2 & 62.8 & 1.5 & 1.1 & -72.2 \\
\hline 8 & $\mathrm{Et}_{2} \mathrm{Zn} / \mathrm{Bnbox}(1 / 0.5)$ & Tol. (3) & -40 & 72 & 26.6 & 25.3 & 0.7 & 1.0 & -70.1 \\
\hline 9 & $\mathrm{Et}_{2} \mathrm{Zn} / \mathrm{Sp}(1 / 1.2)$ & Tol. (3) & 0 & 72 & 60.7 & 59.5 & 2.3 & 1.2 & -64.4 \\
\hline 10 & $\mathrm{Et}_{2} \mathrm{Zn} / \mathrm{Sp}(1 / 1.2)$ & Tol. (3) & -40 & 72 & 32.2 & 32.1 & 0.9 & 1.2 & -74.8 \\
\hline 11 & AIBN & Tol. (2) & 60 & 24 & 100 & 97.3 & 5.3 & 1.5 & -38.3 \\
\hline
\end{tabular}

Abbreviations: AIBN, 2, 2'-azobisisobutylonitrile; THF, tetrahydrofuran, Tol., toluene.

${ }^{\mathrm{a}} 0.3 \mathrm{~g}$

b $[$ Organometal] $/[$ monomer] $=0.1,[\mathrm{AlBN}] /[$ monomer $]=0.05$.

${ }^{\mathrm{C}} \mathrm{By}{ }^{1} \mathrm{H}$ nuclear magnetic resonance in $\mathrm{CDCl}_{3}$.

${ }^{\mathrm{d}} n$-Hexane-insoluble part.

eBy gel permeation chromatography in THF.

${ }^{\mathrm{f}} \mathrm{C}=0.1 \mathrm{~g} \mathrm{dl}^{-1}, \mathrm{l}=10 \mathrm{~cm}$ in THF.

Table 2 Asymmetric anionic and radical polymerization of (S)-A15C5PAMI

\begin{tabular}{|c|c|c|c|c|c|c|c|c|c|}
\hline Run & Initiator ${ }^{b}$ & Polym. solv. (ml) & Polym. temp. $\left({ }^{\circ} \mathrm{C}\right)$ & Polym. time (h) & Conv. $(\%)^{c}$ & Yield $(\%)^{\mathrm{d}}$ & $M_{\mathrm{n}} \times 10^{-3 \mathrm{e}}$ & $M_{\mathrm{w}} / M_{\mathrm{n}}^{\mathrm{e}}$ & {$[\alpha]_{435}^{25}(\text { deg. })^{f}$} \\
\hline 1 & n-BuLi & Tol. (3) & 0 & 24 & 100 & 94.8 & 2.6 & 1.4 & -105.8 \\
\hline 2 & n-BuLi & Tol. (3) & -40 & 72 & 100 & 99.2 & 2.1 & 1.4 & -84.9 \\
\hline 3 & n-BuLi/Bnbox (1/1.2) & Tol. (3) & 0 & 24 & 100 & 98.6 & 2.2 & 1.3 & -86.9 \\
\hline 4 & n-BuLi/Bnbox (1/1.2) & Tol. (3) & -40 & 72 & 100 & 98.7 & 1.6 & 1.1 & -68.5 \\
\hline 5 & n-BuLi/Sp (1/1.2) & Tol. (3) & 0 & 24 & 100 & 98.3 & 1.4 & 1.1 & -70.7 \\
\hline 6 & n-BuLi/Sp (1/1.2) & Tol. (3) & -40 & 72 & 100 & 99.0 & 1.3 & 1.1 & -73.8 \\
\hline 7 & AIBN & Tol. (2) & 60 & 24 & 100 & 99.2 & 5.6 & 3.2 & -94.6 \\
\hline
\end{tabular}

Abbreviations: AIBN, 2, 2'-azobisisobutylonitrile; Tol., toluene.

a $0.3 \mathrm{~g}$.

b $[$ Organometal $] /[$ monomer $]=0.1,[\mathrm{AIBN}] /[$ monomer $]=0.05$

${ }^{\mathrm{C} B y}{ }^{1} \mathrm{H}$ nuclear magnetic resonance in $\mathrm{CDCl}_{3}$.

${ }^{\mathrm{d}} n$-Hexane-insoluble part.

eBy gel permeation chromatography in THF.

${ }^{\mathrm{f}} \mathrm{C}=0.1 \mathrm{~g} \mathrm{dl}^{-1}, \mathrm{l}=10 \mathrm{~cm}$ in THF. 

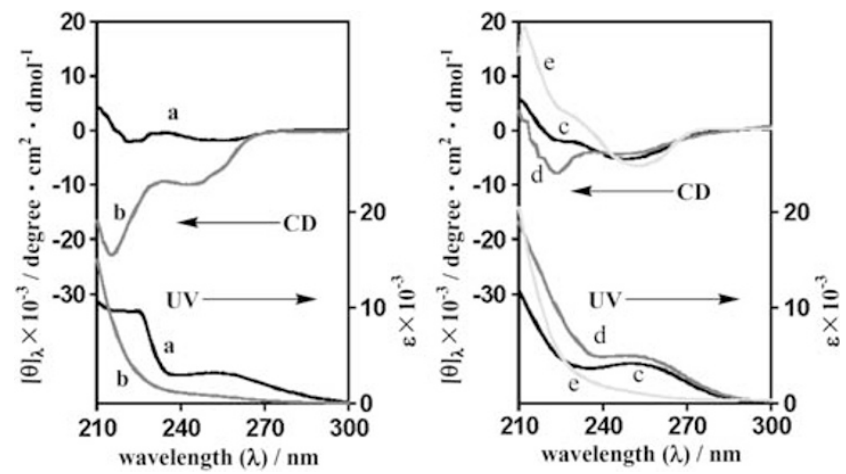

Figure 1 Circular dichroism (CD) and ultraviolet (UV) spectra of

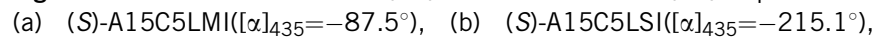
(c) poly((S)-A15C5LMI) ( $n$-BuLi/(S, S)-Bnbox in toluene (Tol.) at $-40^{\circ} \mathrm{C}$, $\left.[\alpha]_{435}=42.7^{\circ}\right)$, (d) poly $((S)-A 15 C 5 L M I)\left(E t_{2} Z n /(-)\right.$-sparteine in Tol. at $0^{\circ} \mathrm{C}$, $\left.[\alpha]_{435}=-64.4^{\circ}\right)$ and (e) poly((S)-A15C5LMI) (2, 2'-azobisisobutylonitrile in Tol. at $60^{\circ} \mathrm{C},[\alpha]_{435}=-38.3^{\circ}$ ).
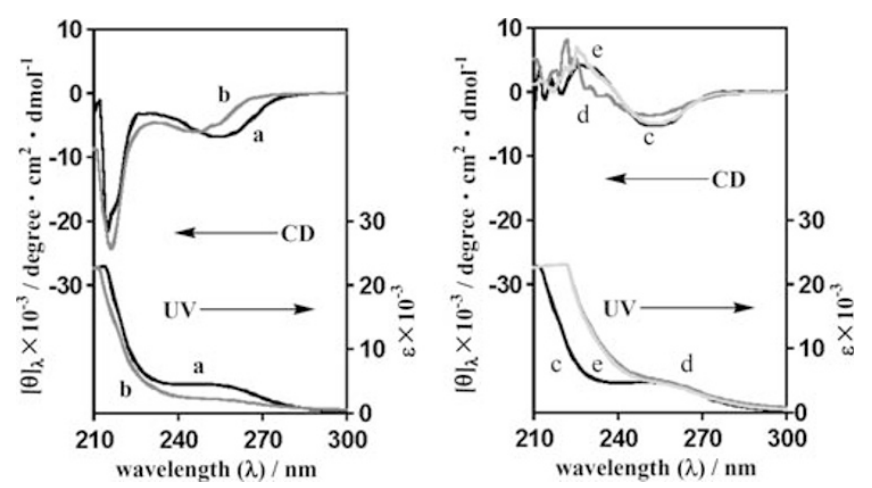

Figure 2 Circular dichroism (CD) and ultraviolet (UV) spectra of (a) (S)-A15C5PAMI ([ $\left.\alpha]_{435}=-212.3^{\circ}\right)$, (b) (S)-A15C5PASI $\left([\alpha]_{435}=-218.1^{\circ}\right)$, (c) poly((S)-A15C5PAMI) ( $n$-BuLi in toluene (Tol.) at $0^{\circ} \mathrm{C},[\alpha]_{435}=-105.8^{\circ}$ ), (d) poly((S)-A15C5PAMI) ( $n$-BuLi/(S, S)-Bnbox in Tol. at $-40^{\circ} \mathrm{C}$, $\left.[\alpha]_{435}=-68.5^{\circ}\right)$ and (e) poly((S)-A15C5PAMI) (2, 2'-azobisisobutylonitrile in Tol. at $\left.60^{\circ} \mathrm{C},[\alpha]_{435}=-94.6^{\circ}\right)$.

same polymerization temperature, the specific optical rotations of the polymers obtained using a complex of $n$-BuLi and a chiral ligand shifted to a positive direction compared with those of the polymers obtained with only $n$-BuLi (Table 2 ). The specific optical rotations of these polymers were affected to a large degree by the main chains, stereocontrolled with a complex of $n$-BuLi and the chiral ligand.

Figure 2 shows the CD and UV spectra of $(S)$-A15C5PAMI, $(S)$ A15C5PASI and the poly $((S)$-A15C5PAMI)s. The CD spectra of $(S)$ A15C5PAMI and $(S)$-A15C5PASI exhibited negative cotton effects around 220 and $260 \mathrm{~nm}$, which were mainly attributable to the $n-\pi^{*}$ transition of the carbonyl groups and the $\pi-\pi^{*}$ transition of the phenyl group. CD peaks of poly((S)-A15C5PAMI)s were significantly different from those of the model compound, especially around $220 \mathrm{~nm}$. This indicates that asymmetric induction took place on the main chain.

\section{Structures of polymers}

Figure 3 shows ${ }^{13} \mathrm{C}$ NMR spectra of poly $((S)$-A15C5LMI) obtained with various initiators. Peaks for methine carbons of the main chain, carbonyl group of side chain and carbonyl groups of maleimide ring appeared at approximately 36-46, 166-170 and 174-178 p.p.m., a
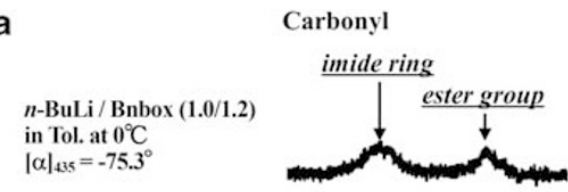

b

n-BuLi / Bnbox (1.0/1.2) in Tol. at $-40^{\circ} \mathrm{C}$ $|\alpha|_{435}=-42.7^{\circ}$

C

AIBN in Tol. at $60^{\circ} \mathrm{C}$ $[\alpha]_{435}=-38.3^{\circ}$
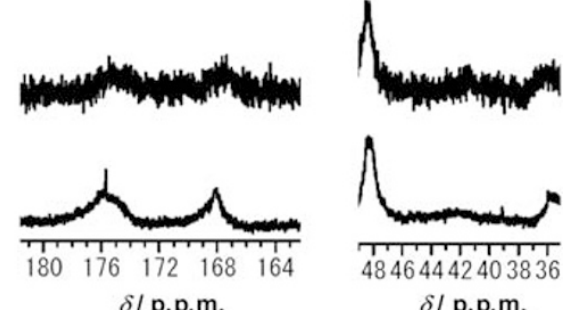

Figure $3{ }^{13} \mathrm{C}$ nuclear magnetic resonance (NMR) spectra of poly((S)A15C5PAMI) initiated with (a) $n$-BuLi/(S, S)-Bnbox in toluene (Tol.) at $0{ }^{\circ} \mathrm{C}$ $\left([\alpha]_{435}=-75.3^{\circ}\right)$, (b) $n$-BuLi/(S, S)-Bnbox in Tol. at $-40^{\circ} \mathrm{C}\left([\alpha]_{435}=-42.7^{\circ}\right)$ and (c) $2,2^{\prime}$-azobisisobutylonitrile (AIBN) in Tol. at $60^{\circ} \mathrm{C}\left([\alpha]_{435}=-38.3^{\circ}\right)$.

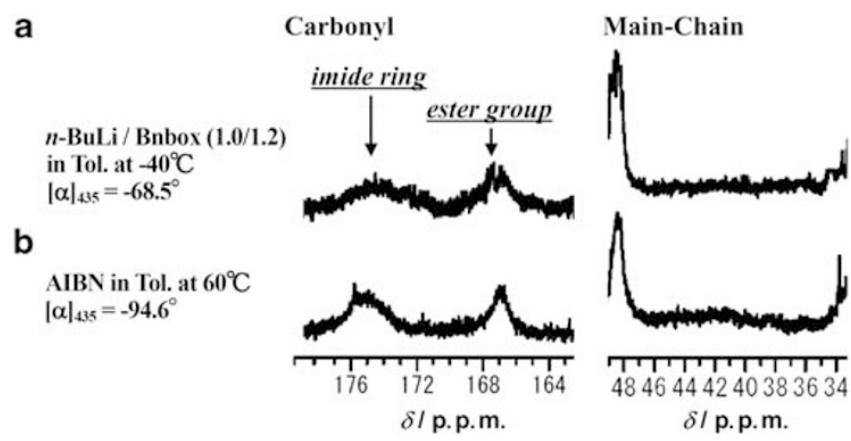

Figure $4{ }^{13} \mathrm{C}$ nuclear magnetic resonance (NMR) spectra of poly((S)A15C5PAMI) initiated with (a) $n$-BuLi/(S, S)-Bnbox in toluene (Tol.) at $-40^{\circ} \mathrm{C}\left([\alpha]_{435}=-68.5^{\circ}\right)$ and (b) $2,2^{\prime}$-azobisisobutylonitrile (AIBN) in Tol. at $60^{\circ} \mathrm{C}\left([\alpha]_{435}=-94.6^{\circ}\right)$.

respectively. These peak patterns were similar. Thus, it was difficult to estimate the detail structures of polymers obtained with radical and anionic polymerizations.

Figure 4 depicts ${ }^{13} \mathrm{C}$ NMR spectra of poly $((S)$-A15C5PAMI) obtained with various initiators. Peaks for the methine carbons of the main chain, the carbonyl group of the side chain and the carbonyl groups of the maleimide ring appeared at approximately 36-46, 166170 and $172-178$ p.p.m., respectively. The poly $((S)-A 15 C 5 P A M I)$ showed an NMR spectrum similar to that of the methine carbons of the main chain of poly $((S)-A 15 C 5 L M I)$. The result suggested that the crown ether group affected polymer structures.

Additional effect of $(S)$ - or $(R)$-Cyc on the polymer obtained by the radical method

To clarify the influence of host-guest complexation on the structure, the CD measurement of poly $((S)-A 15 C 5 L M I)$ was carried out in the presence of chiral guest molecules. Figure 5 shows the $\mathrm{CD}$ and UV spectra of poly $((S)$-A15C5LMI) initiated with 2, 2' -azobisisobutylonitrile (run 11, Table 1) using $(S)$ - or $(R)$-Cyc as chiral guests in $\mathrm{CH}_{3} \mathrm{CN} /$ chloroform $(1 / 1)$ at $25^{\circ} \mathrm{C}$. By increasing the amount of $(R)$-Cyc, the intensity of the cotton effect due to the carbonyl groups of maleimide around $240-270 \mathrm{~nm}$ greatly increased. On the contrary, the CD spectra of $\operatorname{poly}((S)-A 15 C 5 L M I)$ were nearly unchanged by the addition of $(S)$-Cyc. This indicates that the 

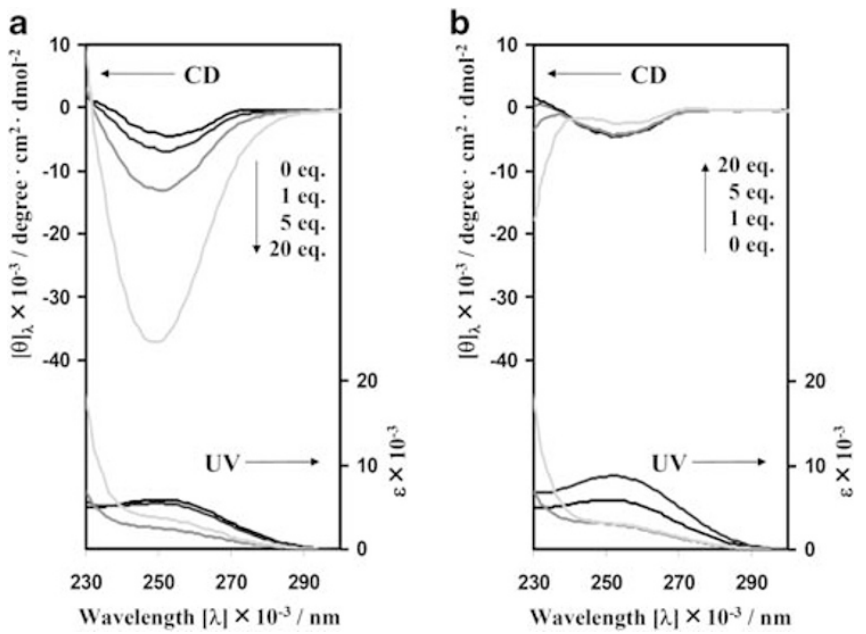

Figure 5 Circular dichroism (CD) and ultraviolet (UV) spectra of poly((S)A15C5LMI) initiated with 2, 2'-azobisisobutylonitrile (run 11 in Table 1) in the presence of (a) (R)-Cyc and (b) (S)-Cyc.

optically active poly $((S)$-A15C5LMI) was selectively complexed with $(R)$-Cyc. However, the cotton effects of the polymer did not change when a chiral ammonium salt was added. Previous research indicates that chiral ammonium salts have an effect on polymers with flexible main chain structures, such as poly(phenylacetylene) and poly(isocyanate).${ }^{17-25}$ In this study, we investigated the effect of adding a chiral ammonium salt to the maleimide polymer with a rigid main chain structure. Because the main chain structure is rigid, there is no space between the bulky $\mathrm{N}$-substituents, including a crown ether unit. Therefore, the chiral ammonium salt may be difficult to coordinate with the crown ether due to the steric hindrance between the side chains.

\section{CONCLUSIONS}

1. Novel chiral $N$-substituted maleimides bearing an aza 15 -crown-5 ether group ((S)-A15C5LMI and (S)-A15C5PAMI) were synthesized and anionically polymerized with an organometal/chiral ligand to obtain optically active maleimide polymers.

2. Specific optical rotations and CD spectral patterns of poly $((S)$ A15C5LMI) and poly $((S)-A 15 C 5 P A M I)$ obtained with $n$-BuLi/ $(S, S)$-Bnbox were very different from those of the model compounds, which indicated that asymmetric induction took place on the polymer main chain.

3. Conformational chirality of the polymer main chain was changed by adding $(R)$-Cyc to the polymers obtained from radical polymerization. This indicated that optically active poly $((S)$ A15C5LMI) was selectively complexed with (R)-Cyc.

1 Okamoto, Y., Suzuki, K., Ohta, K., Hatada, K. \& Yuki, H. Optically active poly(triphenylmethyl methacrylate) with one-handed helical conformation. J. Am. Chem. Soc. 101, 4763 (1979)
2 Okamoto, Y., Suzuki, K. \& Yuki, H. Asymmetric polymerization of triphenylmethyl methacrylate by optically active anionic catalysts. J. Polym. Sci. Polym. Chem. Ed. 18, 3043 (1980).

3 Nakano, T., Okamoto, Y. \& Hatada, K. Asymmetric polymerization of triphenylmethyl methacrylate leading to a one-handed helical polymer: mechanism of polymerization. J. Am. Chem. Soc. 114, 1318 (1992).

4 Okamoto, Y. \& Nakano, T. Asymmetric Polymerization. Chem. Rev. 94, 349 (1994).

5 Okamoto, Y., Nakano, T., Kobayashi, H. \& Hatada, K. Asymmetric polymerization of $\mathrm{N}$-phenylmaleimide. Polym. Bull. 25, 5 (1991).

6 Oishi, T., Yamasaki, H. \& Fujimoto, M. Asymmetric polymerization of $\mathrm{N}$-substituted maleimides. Polym. J. 23, 759 (1991).

7 Cubbon, R. C. P. Free radical and anionic polymerization of some $\mathrm{N}$-substituted maleimides. Polymer 6, 419 (1965).

8 Oishi, T., Sase, K., Saeki, K., Yao, S. \& Ohdan, K. Polymerization and copolymerization of $\mathrm{N}$-cyclododecylmaleimide. Polymer 36, 3935 (1995).

9 Oishi, T., Onimura, K., Isobe, Y., Yanagihara, H. \& Tsutsumi, H. Asymmetric anionic polymerization of maleimides bearing bulky substituents. J. Polym. Sci., Part A: Polym. Chem. 38, 310 (2000)

10 Zhou, H., Onimura, K., Tsutsumi, H. \& Oishi, T. Synthesis and chiroptical properties of (S)-(-)- $N$ - $\alpha$-methylbenzylmaleimide polymers containing crystallinity. Polym. J. 33, 227 (2001).

11 Isobe, Y., Onimura, K., Tsutsumi, H. \& Oishi, T. Asymmetric anionic polymerization of $\mathrm{N}$-1-naphthylmaleimide with chiral ligand-organometal complexes in toluene. J. Polym. Sci., Part A: Polym. Chem. 39, 3556 (2001).

12 Isobe, Y., Onimura, K., Tsutsumi, H. \& Oishi, T. Asymmetric polymerization of $\mathrm{N}-1$ naphthylmaleimide with chiral anionic initiator: preparation of highly optically active poly( $N$-1-naphthylmaleimide). Macromolecules 34, 7617 (2001).

13 Isobe, Y., Onimura, K., Tsutsumi, H. \& Oishi, T. Asymmetric polymerization of $\mathrm{N}-1$ anthrylmaleimide with diethylzinc-chiral ligand complexes and optical resolution using the polymer. Polym. J. 34, 18 (2002).

14 Onimura, K., Zhang, Y., Yagyu, M. \& Oishi, T. Asymmetric anionic polymerization of optically active $\mathrm{N}$-1-cyclohexylethylmaleimide. J. Polym. Sci., Part A: Polym. Chem. 42, 4682 (2004).

15 Gao, H., Isobe, Y., Onimura, K. \& Oishi, T. Asymmetric polymerization of ( $\mathrm{S}$ )- $\mathrm{N}$-maleoylL-leucine allyl ester and chiral recognition ability of its polymer as chiral stationary phase for HPLC. Polym. J. 39, 764 (2007).

16 Oishi, T., Gao, H., Nakamura, T., Isobe, Y. \& Onimura, K. Asymmetric polymerizations of $\mathrm{N}$-substituted maleimides bearing L-leucine ester derivatives and chiral recognition abilities of their polymers. Polym. J. 39, 1047 (2007).

17 Azechi, M., Yamabuki, K., Onimura, K. \& Oishi, T. Asymmetric anionic polymerization of maleimide bearing an $\mathrm{N}$-4'-benzo 15 -crown-5 ether with an organometal/chiral ligand complex. Polym. J. 42, 632 (2010).

18 Nonokawa, R. \& Yashima, E. Detection and amplification of a small enantiomeric imbalance in $\alpha$-amino acids by a helical poly(phenylacetylene) with crown ether pendants. J. Am. Chem. Soc. 125, 1278 (2003).

19 Nonokawa, R., Oodo, M. \& Yashima, E. Helicity induction on a poly(phenylacetylene) derivative bearing Aza-15-crown-5 ether pendants in organic solvents and water. Macromolcules 36, 6599 (2003).

20 Morino, K., Oobo, M. \& Yashima, E. Helicity induction in a poly(phenylacetylene) bearing Aza-18-crown-6 ether pendants with optically active Bis(amino acid)s and its chiral stimuli-responsive gelation. Macromolcules 38, 3461 (2005).

21 Nonokawa, R. \& Yashima, E. Helicity induction on a poly(phenylacetylene) derivative bearing Aza-18-crown-6 ether pendants in water. J. Polym. Sci., Part A: Polym. Chem. 41, 1004 (2003).

22 Morino, K., Kaptein, B. \& Yashima, E. Detection of the chirality of $C^{\alpha}$-methylated $\alpha$ amino acids with a dynamic helical poly(phenylacetylene) bearing Aza-18-crown-6 ether pendants. Chirality 18, 717 (2006).

23 Sakai, R., Satoh, T, Kakuchi, R., Kaga, H. \& Kakuchi, T. Macromolecular helicity induction for novel optically inactive poly(phenyl isocyanate) bearing crown ether based on the host-guest complexation. Macromolecules 36, 3709 (2003).

24 Sakai, R., Satoh, T., Kakuchi, R., Kaga, H. \& Kakuchi, T. Helicity induction of polyisocyanate with a crown cavity on the main chain synthesized by cyclopolymerization of $\alpha, \omega$-diisocyanate. Macromolecules 37, 3996 (2004).

25 Sakai, R., Otsuka, I., Satoh, T., Kakuchi, R., Kaga, H. \& Kakuchi, T. Thermoresponsive on-off switching of chiroptical property Induced in poly(4'-ethynylbenzo-15-crown-5)/ $\alpha$-amino acid system. Macromolecules 39, 4032 (2006).

26 Sakai, R., Otsuka, I., Satoh, T., Kakuchi, R., Kaga, H. \& Kakuchi, T. Chiral discrimination of a helically organized crown ether array parallel to the helix axis of polyisocyanate. J. Polym. Sci., Part A: Polym. Chem. 44, 325 (2006).

27 Denmark, S. E., Nakajima, N. \& Nicaise, O. J.- C. Asymmetric addition of organolithium reagents to imines. J. Am. Chem. Soc. 125, 1278 (2003).

28 Denmark, S. E., Nakajima, N., Nicaise, O. J.- C., Faucher, A.- M. \& Edwards, J. P. Preparation of chiral bisoxazolines: observations on the effect of substituents. J. Org. Chem. 60, 4884 (1995).

29 Denmark, S. E., Stavenger, R. A., Faucher, A.- M. \& Edwards, J. P. Cyclopropanation with diazomethane and bis(oxazoline)palladium(II) complexes. J. Org. Chem. 62, 3375 (1997). 